\title{
MicroRNA-21 induces breast cancer cell invasion and migration by suppressing smad7 via EGF and TGF- $\beta$ pathways
}

\author{
MINGLI HAN ${ }^{1,2}$, FANG WANG ${ }^{1}$, YUANTING GU ${ }^{1}$, XINHONG PEI ${ }^{1}$, GUANGCHENG GUO $^{1}$, \\ CHAO YU ${ }^{3}$, LIN LI $^{1}$, MINGZHI ZHU ${ }^{1}$, YOUYI XIONG ${ }^{1}$ and YIMENG WANG ${ }^{4}$ \\ ${ }^{1}$ Department of Breast Surgery; ${ }^{2}$ The Key Laboratory, The First Affiliated Hospital of Zhengzhou University, \\ Zhengzhou, Henan 450052; ${ }^{3}$ Department of Surgery, University-Town Hospital of Chongqing Medical University, \\ Chongqing 400016; ${ }^{4}$ Department of Geriatric Endocrinology, The First Affiliated Hospital of Zhengzhou University, \\ Zhengzhou, Henan 450052, P.R. China
}

Received May 29, 2015; Accepted June 26, 2015

DOI: $10.3892 /$ or.2015.4360

\begin{abstract}
MicroRNA-21 (miR-21) upregulation, smad family member $7(\operatorname{smad} 7)$ downregulation, epidermal growth factor (EGF) and transforming growth factor- $\beta$ (TGF- $\beta$ ) actions contribute to breast cancer cell aggressiveness. However, their correlation and the relevant molecular mechanisms involved remain to be elucidated. The present study was undertaken to determine the association of miR-21, smad7, EGF and TGF- $\beta$ with breast cancer cell invasion and migration and to identify the molecular mechanisms involved using immunohistochemistry and western blot analysis. In the present study, the plasma miR-21 levels were significantly increased in patients with breast cancer, as compared to the controls. Smad7 was confirmed to be a direct target of miR-21, by luciferase reporter and western blot assays. The downregulation of smad7 by miR-21 or sismad7 enhanced EGF-dependent invasion and migration, as well as TGF- $\beta$-dependent invasion and migration. The actions of miR-21 were abrogated by expressing a modified smad7 cDNA resistant to miR-21. Moreover, miR-21, EGF and TGF- $\beta$ combined to markedly increase cancer cell invasion and migration, and this effect was blocked by the combination of erlotinib (an EGF receptor kinase inhibitor) and SB505124 (a type I TGF- $\beta$ receptor inhibitor). A lower smad7 expression was identified in poorly differentiated breast cancers, as compared to well- to moderately differentiated breast cancers. Notably, antagonism of miR-21 decreased breast cancer cell proliferation and tumor growth in mouse models. In conclusion, our results demonstrated that plasma miR-21 levels may serve as a diagnostic marker in breast cancers, whereas miR-21 promotes breast cancer cell proliferation
\end{abstract}

Correspondence to: Dr Mingli Han, Department of Breast Surgery, The First Affiliated Hospital of Zhengzhou University, No.1 Jianshe Road, Zhengzhou, Henan 450052, P.R. China

E-mail:minglihan@126.com

Key words: miR-21, smad7, epidermal growth factor, TGF- $\beta$, breast cancer and invasion by suppressing smad7, which enhances EGF and TGF- $\beta$ pathways.

\section{Introduction}

Metastasis accounts for the majority of mortalities of cancer patients. Thus, it is crucial to gain an understanding of the relevant molecular and cellular mechanisms involved in the metastatic process. The progression of cancer metastasis depends on various factors, including major driver mutations in key regulatory genes (ASPP2, smad7, PIK3CA, PTEN) (1-5), microRNAs (miRNAs) (6), cancer stem cells (CSCs) (7) and the aberrant activation of multiple signaling pathways as a consequence of the overexpression of multiple tyrosine kinase receptors, such as the epidermal growth factor (EGF) receptor (EGFR) and its ligands (8) and excessive production of transforming growth factor- $\beta$ (TGF- $\beta$ ) isoforms (9).

The growth factor control of cell fate is a pivotal step in cancer progression. The high expression of EGFR in various types of cancer has been associated with metastatic tumors and poor clinical outcomes $(10,11)$. The EGFR family members lead to enhanced tyrosine kinase activity of the receptor complexes and activation of multiple signaling pathways, such as phosphatidylinositol 3'-kinase (PI3K), mitogen-activated protein kinase (MAPK), p38 MAPK, Src and Crk (12-15). TGF- $\beta$, a key regulator in epithelial-mesenchymal transdifferentiation (EMT) and radiation resistance, also plays a major role in the regulation of tumor initiation, progression and metastasis (16). TGF- $\beta$ can enhance the invasion and migration of breast cancer cells and stimulate breast cancer cell proliferation $(17,18)$. It activates serine-threonine kinases, which act through the smads signaling pathways as well as non-smad signaling cascades including MAPK/ERK, Rho-family of GTPases and PI3K/ AKT on the tumor microenvironment in breast cancers $(19,20)$. These results indicate that EGF-TGF- $\beta$ 'cross talk' is important with respect to cell-autonomous effects in breast cancer.

miRNAs are a family of small non-coding RNA molecules that regulate gene expression by base pairing to the 3'-UTR of the target mRNA (21). Recently, a series of miRNAs have been shown to play a critical role in the progression and metastasis of human malignancies (22-24). MicroRNA-21 (miR-21) 
is one of the first miRNAs detected in the human genome, and is also known to be upregulated in all types of human malignancies (25). Previous findings showed that miR-21 overexpression in breast cancer cells is a marker of the disease aggressiveness $(26,27)$. miR-21 regulates cell proliferation, invasion and migration in the majority of cancer cells through its downstream target proteins, such as tumor suppressor gene tropomyosin 1 (TPM1), programmed cell death 4 (PDCD4), MARCKS, maspin and phosphatase and tensin homolog deleted on chromosome ten (PTEN) (4,28-30). However, whether and how miR-21 and its target $\operatorname{smad} 7$ co-operate to orchestrate breast cancer cell invasion and migration remains to be determined.

On the basis of the above evidence, it appears that miR-21, smad7, EGF and TGF- $\beta$ are completely or partially involved in the invasion and migration process of breast cancer cells. The present study was undertaken determine the association of miR-21, smad7, EGF and TGF- $\beta$ with breast cancer cell invasion and migration to provide insights into the causal mechanisms of breast cancer invasion and metastasis.

\section{Materials and methods}

RT-qPCR assays and cell culture. Plasma from 16 normal controls, 20 patients with fibroadenoma and 20 breast cancer patients (19 patients with infiltrating ductal carcinoma and 1 patient with invasive lobular carcinoma) was obtained from the Department of Breast Surgery, The First Affiliated Hospital of Zhengzhou University (Henan, China), from September, 2013 to May, 2014. The subjects included in the three groups voluntarily joined the present study after providing informed consent. The experimental procedure was carried out in accordance with the Declaration of Helsinki and was approved by the Medical Research Ethics Committee of the First Affiliated Hospital of Zhengzhou University (approval no.: 2013-MR-0045). The miR-21 reverse transcription (RT) primer and RT-qPCR primers used were described in a previous study (31). miRNAs were isolated from $50 \mathrm{ml}$ of plasma using a mirVana miRNA isolation kit (Applied Biosystems, Foster City, CA, USA). RT-qPCR was performed to measure the expression of mature miR-21 in cells, as previously described (31). miR-21 levels were normalized to U6 levels.

For mRNAs, total RNA from cells was isolated using TRIzol reagent (Invitrogen, Carlsbad, CA, USA). RT-qPCR reactions were carried out as previously described (31). $\beta$-actin was used as an endogenous control. MCF-7 cells were cultured as previously described (31).

Constructions. The LightSwitch smad7 3'-UTR reporter (Switchgear Genomics, Menlo Park, CA, USA) was utilized to assess whether there is a direct interaction between miR-21 and smad7 3'-UTR. Site-directed mutagenesis kits (Stratagene, La Jolla, CA, USA) were used to introduce a three-base pair mutation in the seed-binding site of smad7 3'-UTR. The pCMV-SPORT6-smad7 cDNA construct used in the smad7 rescue experiment was purchased from Open Biosystems (Huntsville, AL, USA).

Cell transfection. Human hsa-miR-21 (accession no.: MIMAT0000076) mimics and negative control, and antagomir and negative control were purchased from Ribobio (Guangzhou, China). The cells were seeded in 6-well plates (50-60\% confluency). miR-21 mimics or negative control, and miR-21 antagomir or its negative control were transfected into MCF-7 cells, as previously described $(4,31)$. Sismad7 or the scramble control siRNA sequence (control) was designed, produced and annealed by Ribobio, and designed to target smad7 (gene ID: 4092) was used to silence smad7 in MCF-7 cells. For smad7 rescue experiments, MCF-7 cells were transfected with $40 \mathrm{nM}$ miR-21 mimics and $250 \mathrm{ng}$ pCMV-SPORT6-smad7 cDNA (Invitrogen) and Lipofectamine ${ }^{\mathrm{TM}}$ 2000, which was used in all the transfection studies. After 3 days of transfection, the transfected cells were measured.

Luciferase reporter assay. The cells in 24-well plates (60-70\% confluency) were co-transfected with miR-21 mimics (40 nM) and smad7 3'-UTR reporter (200 ng). Luciferase activity was measured after $24 \mathrm{~h}$, according to the manufacturer's instructions, using a Dual-Glo luciferase assay system (Promega, Madison, WI, USA).

Western blot analysis. Cells in the 6-well plates (60-70\% confluency) were lysed using RIPA lysis buffer (Sijiqing, Hangzhou, China). According to our previous studies $(4,31)$, $50 \mu \mathrm{g}$ of each sample were separated by SDS-PAGE $(10 \%)$ and transferred to PVDF membranes. The membranes were incubated with rabbit anti-human smad7 antibody (no: BA1399, 1:500) and rabbit anti-human $\beta$-actin antibody (no: BA2305, 1:1,000) (both from Boster, Wuhan, China), followed by an HRP-conjugated anti-rabbit IgG secondary antibody (no.: BA1055, 1:2,500; Boster). The samples were visualized by ECL chemiluminescence. $\beta$-actin was used as an endogenous control.

Invasion and migration assay. Cell invasion and migration assays were performed as previously described (31). For the invasion assay, $2.5 \times 10^{4}$ cells were seeded on an $8-\mu \mathrm{m}$ pore size Transwell filter insert (Corning Inc, Corning, NY, USA) coated with ECM (1:7.5; Sigma, St. Louis, MO, USA), while the cell migration assay was not coated with ECM. After $48 \mathrm{~h}$ of incubation at $37^{\circ} \mathrm{C}$ and $5 \% \mathrm{CO}_{2}$, cells adherent to the upper surface of the filter were removed and counted.

Immunohistochemistry. Paraffin-embedded human breast cancer tissues were obtained from the Department of Breast Surgery, The First Affiliated Hospital of Zhengzhou University, and $5-\mu \mathrm{m}$ sections were stained for smad7 using the rabbit antihuman smad7 antibody (no.: BA1399, 1:100; Boster), as previously described (32).

Xenografted mouse model. Four-week-old BALB/c nude mice were obtained from a Shanghai Animal Laboratory (Shanghai, China). Animal welfare and experimental procedures were carried out in accordance with the Guide for the Care and Use of Laboratory Animals and were approved by the Animal Ethics Committee of The First Affiliated Hospital of Zhengzhou University (approval no.: 2013-MR-0045). Xenografted mice were developed by injecting anti-miR-21 MCF-7 cells or its control cells (the total cell number in each injection was $4 \times 10^{6}$ ) to the left side fat-pad of each nude mouse. The tumor volume 


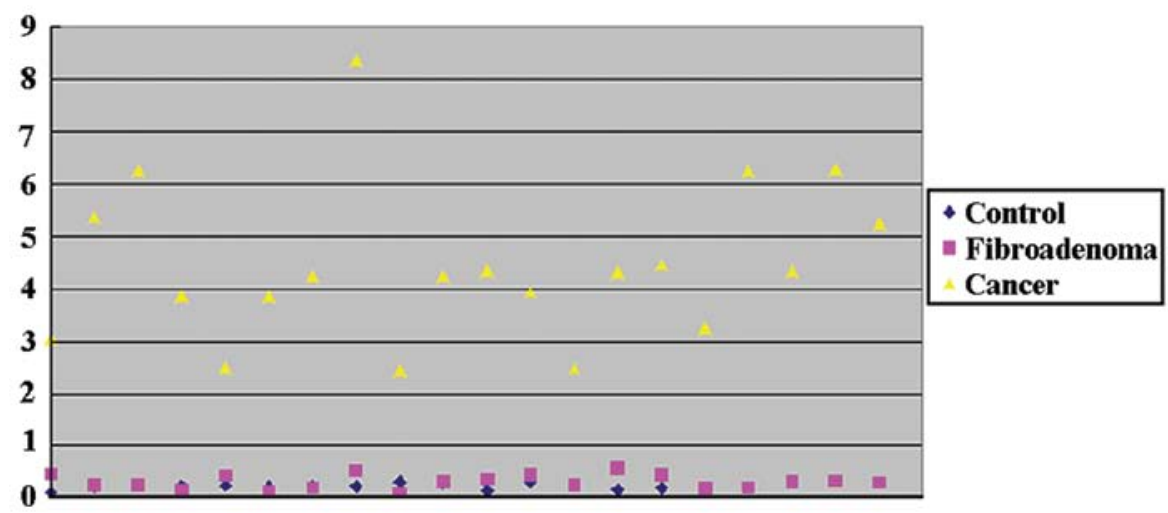

Figure 1. miR-21 is overexpressed in the plasma of patients with breast cancer. The relative levels of miR-21 were significantly overexpressed in patients with breast cancer, as compared to the normal control group $(\mathrm{P}=0.0188)$ or the fibroadenoma group $(\mathrm{P}=0.0192) \mathrm{using} \mathrm{RT}-\mathrm{qPCR}$.

was determined weekly using digital caliper measurements and was calculated using the formula: V (volume; $\mathrm{mm}^{3}$ ) $=1 / 2 \times \mathrm{LD}$ (longest diameter) $2 \times \mathrm{SD}$ (shortest diameter). After five weeks, the mice were sacrificed and the tumors were measured and analyzed.

Statistical analysis. Results are presented as mean \pm SD. Statistical differences between the groups were assessed using Student's t-test, one- or two-way ANOVA, as indicated, by using statistical analysis software SPSS 17.0. P $\leq 0.05$ was considered statistically significant.

\section{Results}

miR-21 is overexpressed in the plasma of patients with breast cancer. To confirm that miR-21 was overexpressed in the plasma of patients with breast cancer, we assayed the relative levels of miR-21 in the plasma of 16 normal controls, 20 patients with fibroadenoma and 20 patients with breast cancer, using RT-qPCR. The relative expression of miR-21 was $4.44153 \pm 1.46336$ in breast cancer patients, significantly overexpressed as compared to $0.22116 \pm 0.05622$ in the normal control group ( $>20$-fold; $\mathrm{P}=0.0188$; Fig. 1 ) or $0.31409 \pm 0.13237$ in the fibroadenoma group ( $>14$-fold; $\mathrm{P}=0.0192$; Fig. 1).

Smad7 is a direct downstream target of $m i R-21$. According to web-based predictive software (http://www.targetscan.org/ and http://www.mirbase.org/) and data from other groups $(33,34)$, smad7 is one of the downstream targets of miR-21 (Fig. 2A). To determine whether $\operatorname{smad} 7$ is a direct target of miR-21 during breast cancer cell invasion and migration, luciferase assays were performed using smad7 3'-UTR. The luciferase assays showed that miR-21 only reduced luciferase activity in cells containing wild-type smad7 3'-UTR, but not in cells containing mutant 3 '-UTR (the mutated nucleotide is marked as red; Fig. 2B and C).

The effects of miR-21 on smad7 expression were further analyzed to determine whether miR-21 regulates smad7 during cancer cell invasion and migration. Firstly, miR-21 mimics was transfected into MCF-7 cells. The relative expression of miR-21 was $1.48398 \pm 0.31843$ in MCF-7/miR-21 cells significantly upregulated as compared to $0.14668 \pm 0.03017$ in the negative control group ( $>10$-fold; $\mathrm{P}=0.0171$; Fig. $2 \mathrm{D})$, which suggests that miR-21 mimics may enhance the activity of miR-21 in MCF-7 cells, through various processes such as gain-offunction. The results showed that miR-21 overexpression significantly decreased the protein level of smad7 (Fig. 2E). Notably, the mRNA level of smad7 did not change in the miR-21-overexpressed cells ( $\mathrm{P}=0.18697$, Fig. $2 \mathrm{~F})$.

miR-21 modulates the actions of EGF and (or) TGF- $\beta$, and enhances breast cancer invasion and migration. To determine whether miR-21 enhanced breast cancer invasion and migration, and whether it modulated the actions of EGF or TGF- $\beta$, MCF-7/miR-21 and control cells were treated with EGF (1 nM) or TGF- $\beta(0.5 \mathrm{nM})$ and measured using Transwell migration and invasion assay. In MCF-7 cells, EGF enhanced invasion $(\mathrm{P}=0.0006$, Fig. 3A) and migration $(\mathrm{P}=0.01851$, Fig. 3B), TGF- $\beta$ enhanced invasion $(\mathrm{P}=0.00586$, Fig. $3 \mathrm{~A})$ and migration $(\mathrm{P}=0.0079$, Fig. 3B), and their combined action was greater than that of either growth factor alone (invasion: $\mathrm{P}=0.00357$, Fig. 3A; migration: $\mathrm{P}=0.0038$, Fig. 3B).

Overexpression of miR-21 increased cell invasion $(\mathrm{P}=0.00126$, Fig. 3A) and migration $(\mathrm{P}=0.00274$, Fig. 3B) in MCF-7 cells, enhanced EGF-mediated invasion $(\mathrm{P}=0.00771$, Fig. 3A) and migration $(\mathrm{P}=0.01518$, Fig. 3B) and TGF- $\beta$-mediated invasion ( $\mathrm{P}=0.00189$, Fig. $3 \mathrm{~A}$ ) and migration $(\mathrm{P}=0.00152$, Fig. 3B). The combination of the two growth factors exerted a significantly greater stimulatory effect on invasion and migration in MCF-7 cells with high miR-21 levels (invasion: $\mathrm{P}=0.00929$, Fig. 3A; migration: $\mathrm{P}=0.00294$, Fig. 3B).

Smad7 is a negative regulator of breast cancer invasion and migration, as well as the actions of EGF and (or) TGF- $\beta$. To determine whether depletion of PTEN affected breast cancer invasion and migration, as well as the actions of EGF and (or) TGF- $\beta$, smad7 siRNA ( $\operatorname{sismad} 7)$, which targeted smad7 or the control Ssismad7 was transfected into MCF-7 cells. After $24 \mathrm{~h}$, the cells were treated with EGF and (or) TGF- $\beta$, and measured uisng Transwell migration and invasion assays, as described earlier. We found that sismad7 significantly downregulated the expression of smad7 (Fig. 4A), as compared to the control groups. Notably, smad7 silencing by sismad7 enhanced breast cancer cell invasion ( $\mathrm{P}=0.03102$, Fig. 4B) and migration $(\mathrm{P}=0.00281$, Fig. 4C) in MCF-7 cells, and increased EGF-mediated invasion 


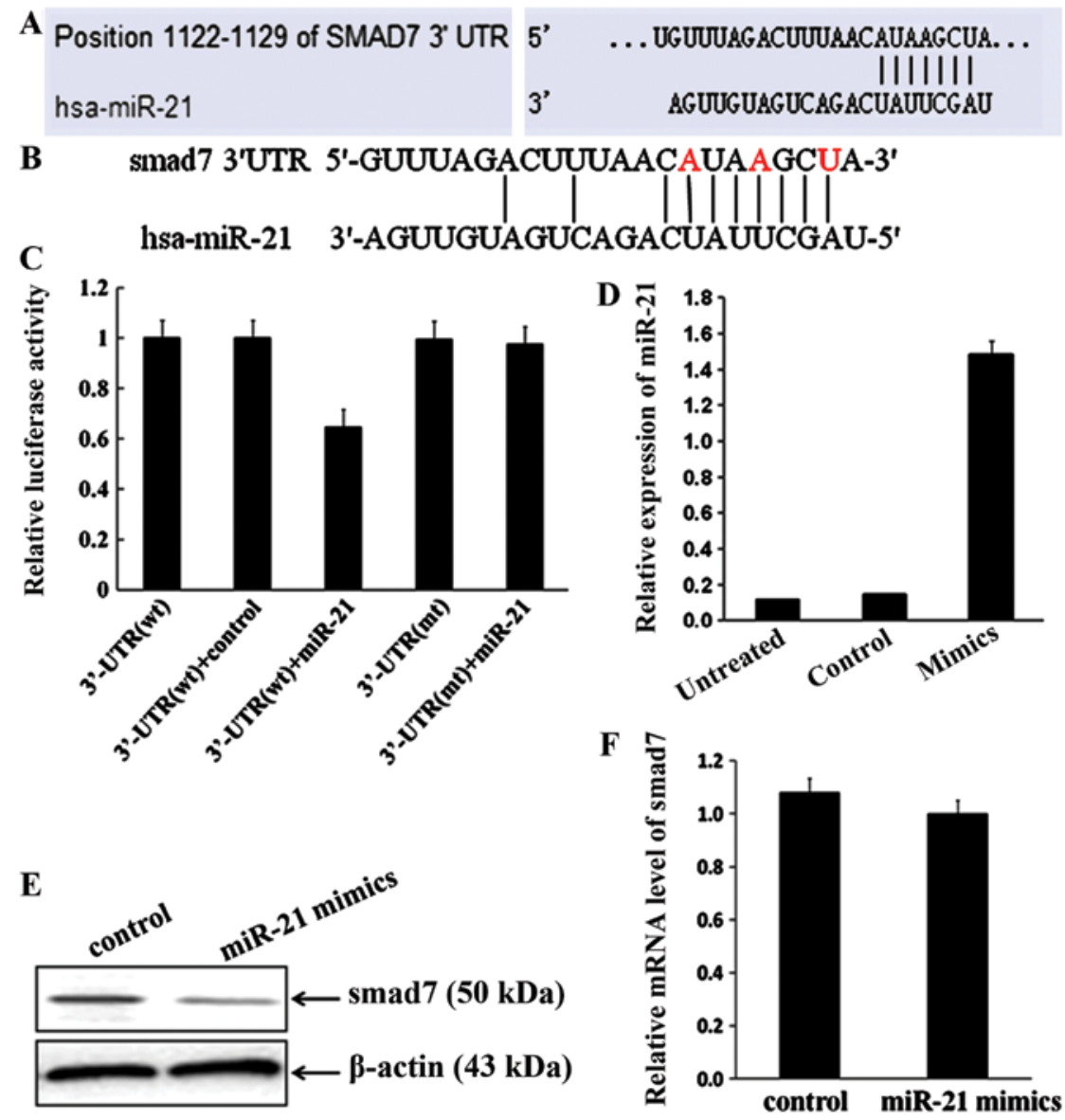

Figure 2. miR-21 regulates the smad7 protein level by inhibiting translation. (A) According to web-based predictive software, miR-21 targets 3'-UTR of smad7 mRNA. (B and C) miR-21 only affects the wild-type 3'-UTR of smad7, but not on the mutant-type (the red nucleotides are mutant to cytosine), as determined by the luciferase assays. (D) MCF-7 cells treated with hsa-miR-21 mimics increased the expression of miR-21, as compared to the control groups (P=0.0015), as determined by RT-qPCR analysis. (E and F) Overexpression of miR-21 reduced the smad7 protein level (E), but did not affect its mRNA level (F).
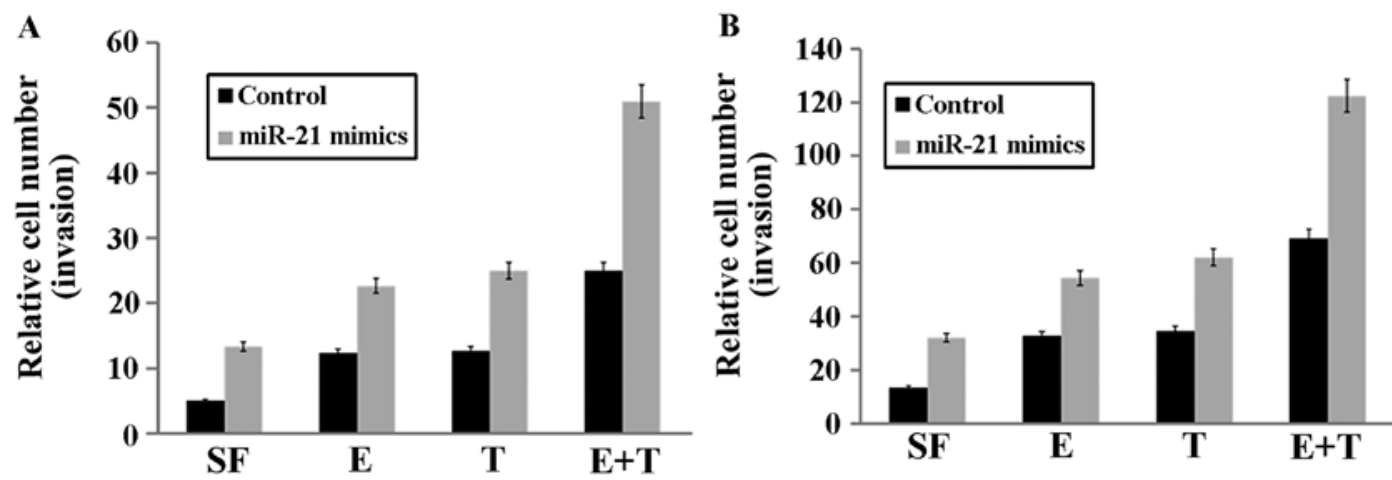

Figure 3. miR-21 modulates the actions of EGF or TGF- $\beta$, as well as enhanced breast cancer cell invasion and migration. (A) In MCF-7 cells, EGF (E, $1 \mathrm{nM}$ ) or TGF- $\beta(\mathrm{T}, 0.5 \mathrm{nM})$ enhanced invasion, compared to the absence SF; and their combined action (E+T) was greater than that of either growth factor alone. Overexpression of miR-21 increased invasion in MCF-7 cells, and enhanced EGF-mediated invasion and TGF- $\beta$-mediated invasion. Furthermore, the combination of the two growth factors exerted a significantly greater stimulatory effect on invasion in cells with high miR-21 levels. (B) The effects of miR-21, EGF and TGF- $\beta$ on breast cancer cell migration, which was similar to the invasion assays. SF, serum-free.

( $\mathrm{P}=0.0301$, Fig. 4B) and migration $(\mathrm{P}=0.01058$, Fig. 4C) and TGF- $\beta$-mediated invasion $(\mathrm{P}=0.01746$, Fig. $4 \mathrm{~B})$ and migration $(\mathrm{P}=0.00706$, Fig. 4C). Moreover, the combination of the two growth factors exerted a significantly greater stimulatory effect on invasion and migration in MCF-7 cells with smad7 silencing (invasion: $\mathrm{P}=0.00577$, Fig. $4 \mathrm{~B}$; migration: $\mathrm{P}=0.003306$, Fig. 4C).
Smad7 downregulation is essential for miR-21-induced stimulation of the actions of EGF and (or) TGF- $\beta$. To confirm that smad7 downregulation was essential for miR-21-induced stimulation of the actions of EGF and (or) TGF- $\beta$, we used the pCMV-SPORT6-smad7 vector, which encodes a smad7 cDNA that is not regulated by miR-21 due to a mutated 3'-UTR binding site. Experiments were carried out in the presence of 
A

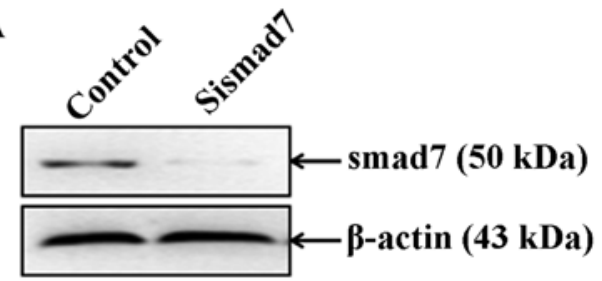

B

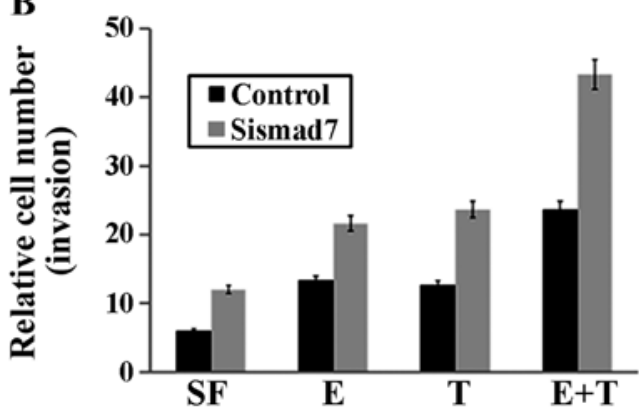

C

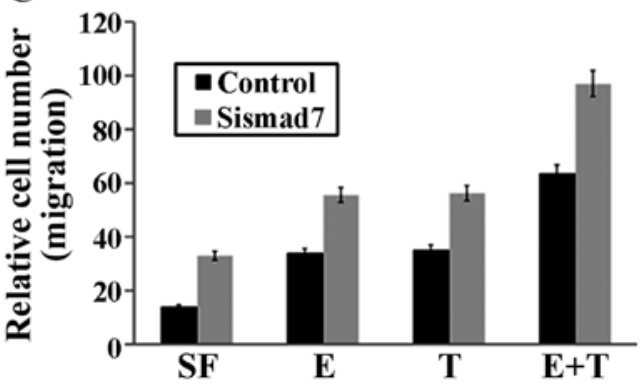

Figure 4. Effects of smad7 downregulation on breast cancer cell invasion and migration. (A) Smad7 silencing. MCF-7 cells were transfected with scrambled control or smad7 siRNAs (sismad7) targeting smad7. (B and C) Downregulation of smad7 increased invasion (and migration) in MCF-7 cells, and enhanced EGF-mediated invasion (and migration) and TGF- $\beta$-mediated invasion (and migration).

EGF or TGF- $\beta$, and in the absence or presence of transfected miR-21mimics using cells expressing an empty vector or the pCMV-SPORT6-smad7 vector. This experimental design allowed for the specific evaluation of the consequence of expressing a smad7 that was resistant to miR-21 upregulation. When pCMV-SPORT6-smad7 was transfected into MCF-7 cells, the stimulatory effect of miR-21 overexpression on EGF- (or TGF- $\beta$-)mediated invasion and migration was partly abrogated (Fig. 5). Thus, smad7 is a functional target of miR-21 whose upregulation promotes EGF (or TGF- $\beta$ )-induced breast cancer cell invasion and migration.

miR-21 regulates breast cancer cell invasion and migration through EGF and TGF- $\beta$ pathways. To investigate the roles of EGF and TGF- $\beta$ pathways in miR-21-regulating breast cancer cell invasion and migration, the MCF-7 cells were transfected with miR-21 mimics at a concentration of $40 \mathrm{nM}$ for $72 \mathrm{~h}$ and then the cells were treated with erlotinib (the inhibitor of EGFR) at $2 \mathrm{mM}$ or SB505124 (the inhibitor of TGF- $\beta$ receptor) at $10 \mathrm{mM}$ for $24 \mathrm{~h}$. The EGFR inhibitor erlotinib $(2 \mathrm{mM})$ partly blocked EGF-induced invasion and migration in the presence of miR-21 in MCF-7 cells (Fig. 6A). Similarly, the TGF- $\beta$ receptor inhibitor SB505124 $(2 \mu \mathrm{M})$ partly blocked TGF- $\beta$ induced invasion and migration in the presence of miR-21
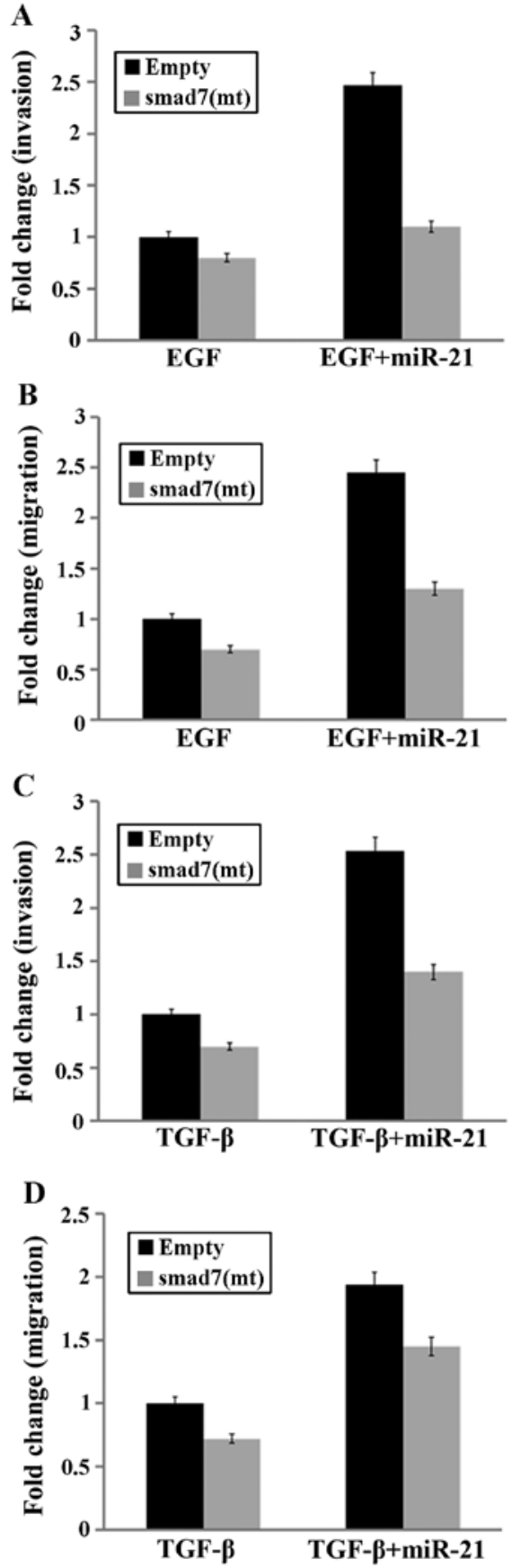

Figure 5. Effects of mutant smad7 on miR-21-enhanced invasion and migration. MCF-7 cells were transfected for $48 \mathrm{~h}$ with the control or miR-21 mimics in combination with empty pCMV-SPORT6 (Empty) or pCMVSPORT6-smad7 carrying a mutated smad7 cDNA $(\operatorname{smad} 7 \mathrm{mt})$ that is resistant to miR-21-induced upregulation. Effects on (A) invasion and (B) migration were then determined using $1 \mathrm{nM}$ EGF. (A) Effects on invasion and (B) migration were then determined using $0.5 \mathrm{nM}$ TGF- $\beta$.

in MCF-7 cells (Fig. 6B). In addition, the effects of miR-21 on EGF (or TGF- $\beta$ ) actions on invasion and migration were markedly attenuated by erlotinib and (or) SB505124 (Fig. 6C), indicating that EGF and TGF- $\beta$ act through their respective receptors to cross talk and enhance breast cancer cell invasion and migration.

Smad7 downregulation in poorly differentiated breast cancer. We determined whether smad7 was expressed in human breast 
A

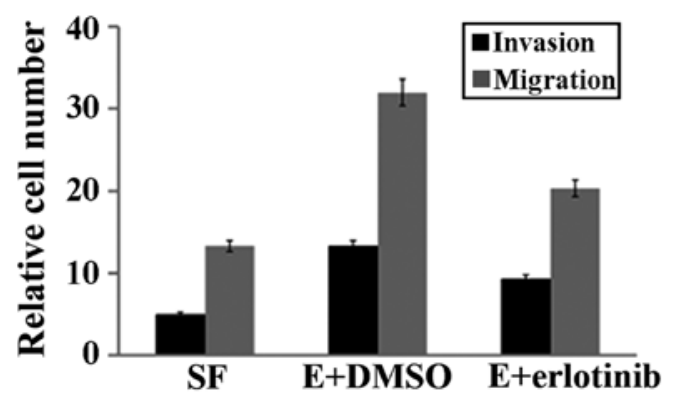

B

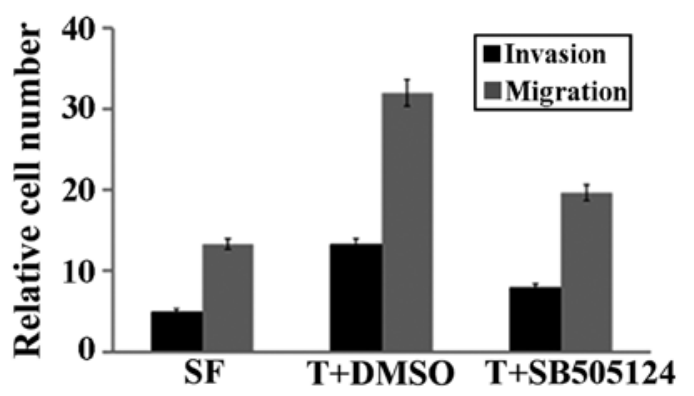

C

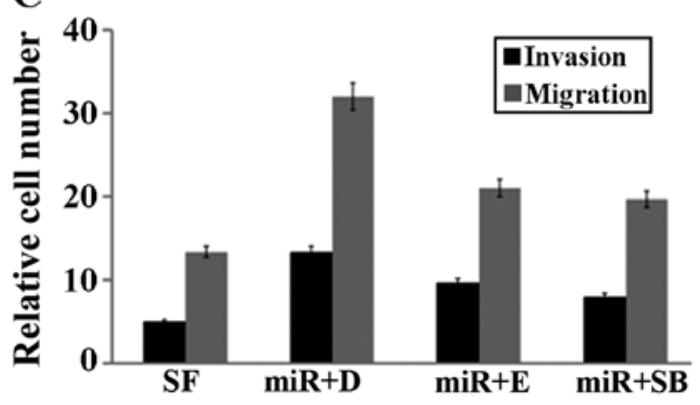

Figure 6. Effects of signaling inhibitors on breast cancer cell invasion and migration, as well as the effects of miR-21 on signaling. (A) Effects of erlotinib (E) on breast cancer cell invasion and migration. (B) Effects of T $\beta$ RI inhibition with SB505124 (SB) on breast cancer cell invasion and migration. (C) Effects of erlotinib and T $\beta$ RI inhibition with SB505124 on miR-21 (miR)-induced breast cancer cell invasion and migration.

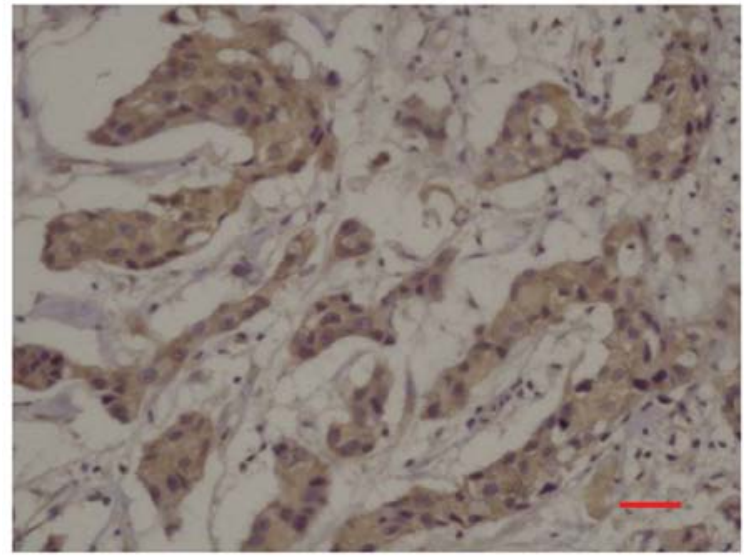

Moderately differentiated

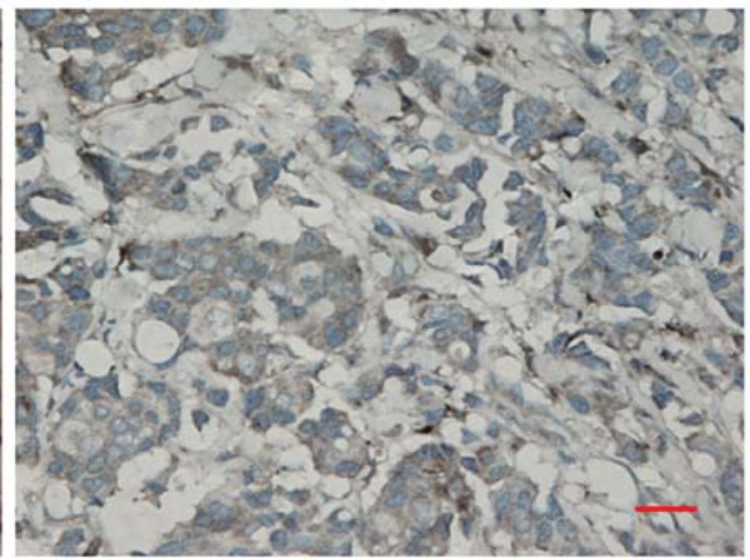

Poorly differentiated

Figure 7. Expression of smad7 protein is weaker in poorly differentiated breast cancer tissues, than moderately differentiated cancers. Immunohistochemistry for smad7 in human breast cancer tissues shows that smad7 exhibits strong immunoreactivity in breast cancers in well- to moderately differentiated cancers. By contrast, the tissues in poorly differentiated breast cancers exhibit weak smad7 immunoreactivity. Scale bars, $50 \mu \mathrm{m}$ (magnification, x200).

cancer samples using the same highly specific antibody that was used in the immunohistochemical experiments. Smad7 was readily visible in the cytoplasm of many cancer cells but not in the adjoining stroma. A high smad7 expression was principally identified in well- to moderately differentiated breast cancer (Fig. 7), whereas a low smad7 expression was observed in poorly differentiated breast cancer (Fig. 7).

Antagonism of miR-21 inhibits breast cancer biological aggressiveness in a nude mouse model. To validate the contribution of miR-21 to breast cancer biological aggressiveness, we carried out an in vivo study in an orthotopic model using nude mice (Fig. 8A). Three-fifths of the mice with miR-21 antagomir MCF-7 cells and four-fifths of the mice with MCF-7 control cells formed breast tumors and the presence of miR-21 antagomir resulted in retarded growth and smaller tumors $(\mathrm{P}=0.00033$, Fig. 8A and $\mathrm{B})$.

\section{Discussion}

In the present study, we found that miR-21 is overexpressed in the plasma of patients with breast cancer. Furthermore, it was demonstrated that smad7 is a direct downstream target of miR-21. Functionally, miR-21 enhanced EGF-mediated 


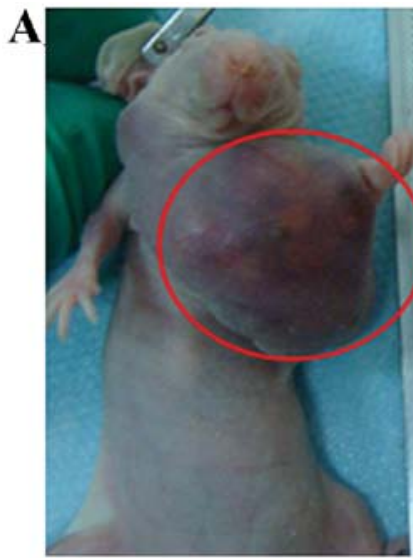

Control

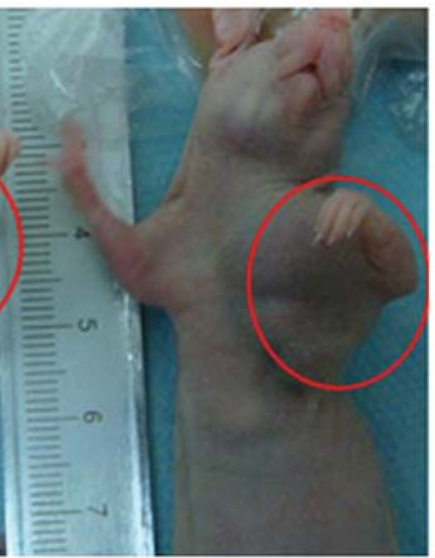

Antagomir

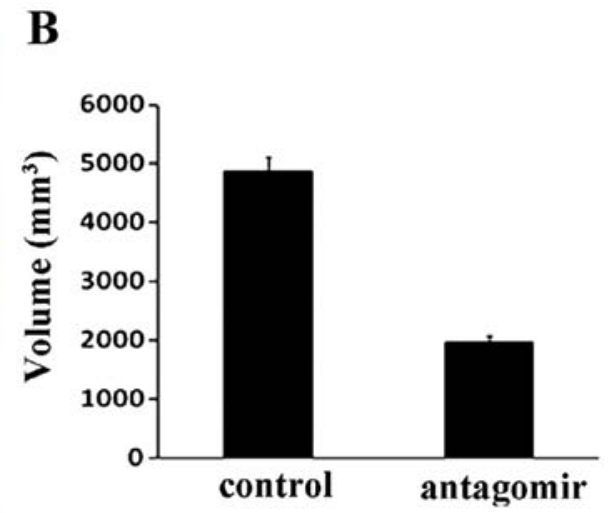

Figure 8. miR-21 overexpression enhances tumor growth. (A) High resolution ultrasound images obtained 5 weeks post-breast cancer cell injection into the left fat pads show that compared with cells transduced with an empty vector (control), miR-21 antagomir significantly decreased tumor growth. Tumors are outlined and representative images from one of the controls and (or) miR-21 antagonism tumors are shown. (B) Quantification of these tumors, calculated via three-dimensional abdominal imaging, shows that miR-21 downregulation significantly decreased tumor volume $(\mathrm{P}=0.00033)$. Data are the mean $\pm \mathrm{SD}$ for all the tumors.

invasion and migration, as well as TGF- $\beta$-mediated invasion and migration in breast cancer cells and these effects were due to miR-21-induced downregulation of smad7.

miR-21 is expressed at high levels in cancer cells in invasive breast cancers (35) and findings of previous studies (including our previous study) have shown that miR-21 plays an important role in breast cancer metastasis (36-38). In the present study, miR-21 was overexpressed in the plasma of patients with breast cancer, demonstrating that miR-21 plays an important role in cancer cell invasion and migration, as metastasis, indicating that plasma miR-21 levels may serve as a diagnostic marker in breast cancer.

Web-based predictive software and data from other groups $(33,34)$ suggest that, $\operatorname{smad} 7$ is one of the downstream targets of miR-21. In the present study, the co-transfection of MCF-7 cells with the smad7 3'-UTR construct and miR-21 precursor caused an approximately $40 \%$ decrease in luciferase activity as compared to the negative control and this suppression of smad7 expression was completely reversed by the threenucleotide substitution in the core binding site. Additionally, he results showed that miR-21 overexpression significantly decreased the level of smad7. Notably, the mRNA level of smad7 was not altered in the miR-21 overexpressed cells. These results demonstrated that $\operatorname{smad} 7$ is a downstream target of miR-21 and miR-21 is capable of decreasing the smad7 level by inhibiting mRNA translation, rather than by mRNA decay.

We determined whether TGF- $\beta$ increased EGF-mediated cell invasion and migration, and whether this effect was markedly enhanced by high levels of miR-21. Of note, the combination of EGF, TGF- $\beta$ and miR-21 induced a marked increase in cancer cell invasion and migration. Thus, miR-21 facilitated deleterious cross-talk between EGF and TGF- $\beta$ in a manner that promotes breast cancer cell invasion and migration. Given that miR-21, EGFR and TGF- $\beta$ are often overexpressed in breast cancers $(12,18,20,26,35,39)$, these observations suggest that suppression of miR-21 may prevent invasion and possibly metastasis in breast cancers, while interrupting deleterious EGF-TGF- $\beta$ interactions that have the potential to contribute to breast cancer cell proliferation in vivo.

We also determined whether smad7 is a functional target of miR-21 whose downregulation promotes EGF-induced (or TGF- $\beta$-induced) breast cancer cell invasion and migration. Specific inhibitors were subsequently used to confirm that EGF and TGF- $\beta$ acted through their respective receptors with respect to their individual and combined stimulatory effects on invasion in the presence of miR-21. Thus, miR-21 exerts multiple deleterious actions in breast cancers, which include the upregulation of EGF and TGF- $\beta$ signaling, thereby contributing to increased breast cancer cell migration and invasion.

Lower smad7 levels were associated with a more poorly differentiated histology and antagonism of miR-21 MCF-7 cells exhibited decreased breast cancer cell proliferation and fat-pad tumor growth. These observations indicate that miR-21 may promote breast cancer cell proliferation, as breast cancer metastasis, by suppressing smad7, which was consistent with the ability of smad7 to inhibit metastasis of mouse mammary carcinoma JygMC(A) cells (40).

In conclusion, the results have shown that by targeting smad7, miR-21 regulates breast cancer cell migration and invasion by promoting EGF and TGF- $\beta$ actions, which suggested that targeting miR-21 may serve to suppress cancer metastasis and to interrupt deleterious EGF-TGF- $\beta$ cross-talk, suggesting a molecular pathway that may relieve the malignant biological behaviors of breast cancers.

\section{Acknowledgements}

The present study was supported in part by the Youth Innovation Foundation of The First Affiliated Hospital of Zhengzhou University, China. We would also like to thank the members of the Department of Breast Surgery, The First Affiliated Hospital of Zhengzhou University, for their critical technical support and financial assistance. 


\section{References}

1. Wang Y, Bu F, Royer C, Serres S, Larkin JR, Soto MS, Sibson NR, Salter V, Fritzsche F, Turnquist C, et al: ASPP2 controls epithelial plasticity and inhibits metastasis through $\beta$-catenin-dependent regulation of ZEB1. Nat Cell Biol 16: 1092-1104, 2014.

2. Lamora A, Talbot J, Bougras G, Amiaud J, Leduc M, Chesneau J, Taurelle J, Stresing V, Le Deley MC, Heymann MF, et al: Overexpression of smad7 blocks primary tumor growth and lung metastasis development in osteosarcoma. Clin Cancer Res 20: 5097-5112, 2014.

3. Markou A, Farkona S, Schiza C, Efstathiou T, Kounelis S, Malamos N, Georgoulias V and Lianidou E: PIK3CA mutational status in circulating tumor cells can change during disease recurrence or progression in patients with breast cancer. Clin Cancer Res 20: 5823-5834, 2014

4. Han M, Liu M, Wang Y, Chen X, Xu J, Sun Y, Zhao L, Qu H, Fan Y and Wu C: Antagonism of miR-21 reverses epithelialmesenchymal transition and cancer stem cell phenotype through AKT/ERK1/2 inactivation by targeting PTEN. PLoS One 7: e39520, 2012.

5. Mulrane L, McGee SF, Gallagher WM and O'Connor DP: miRNA dysregulation in breast cancer. Cancer Res 73: 6554-6562, 2013.

6. Lowery AJ, Miller N, McNeill RE and Kerin MJ: MicroRNAs as prognostic indicators and therapeutic targets: Potential effect on breast cancer management. Clin Cancer Res 14: 360-365, 2008.

7. Geng SQ, Alexandrou AT and Li JJ: Breast cancer stem cells: Multiple capacities in tumor metastasis. Cancer Lett 349: 1-7, 2014.

8. Hardy KM, Booth BW, Hendrix MJ, Salomon DS and Strizzi L: ErbB/EGF signaling and EMT in mammary development and breast cancer. J Mammary Gland Biol Neoplasia 15: 191-199, 2010.

9. Javelaud D, Alexaki VI, Dennler S, Mohammad KS, Guise TA and Mauviel A: TGF- $\beta /$ SMAD/GLI2 signaling axis in cancer progression and metastasis. Cancer Res 71: 5606-5610, 2011.

10. Brand TM, Iida M, Luthar N, Starr MM, Huppert EJ and Wheeler DL: Nuclear EGFR as a molecular target in cancer. Radiother Oncol 108: 370-377, 2013.

11. Boudot A, Kerdivel G, Lecomte S, Flouriot G, Desille M, Godey F, Leveque J, Tas P, Le Dréan Y and Pakdel F: COUP-TFI modifies CXCL12 and CXCR4 expression by activating EGF signaling and stimulates breast cancer cell migration. BMC Cancer 14: 407, 2014

12. Foley J, Nickerson NK, Nam S, Allen KT, Gilmore JL, Nephew KP and Riese DJ II: EGFR signaling in breast cancer: Bad to the bone. Semin Cell Dev Biol 21: 951-960, 2010.

13. Kolch W and Pitt A: Functional proteomics to dissect tyrosine kinase signalling pathways in cancer. Nat Rev Cancer 10 618-629, 2010.

14. Wagner JP, Wolf-Yadlin A, Sevecka M, Grenier JK, Root DE, Lauffenburger DA and MacBeath G: Receptor tyrosine kinases fall into distinct classes based on their inferred signaling networks. Sci Signal 6: ra58, 2013.

15. Ouyang H, Gore J, Deitz S and Korc M: microRNA-10b enhances pancreatic cancer cell invasion by suppressing TIP30 expression and promoting EGF and TGF- $\beta$ actions. Oncogene 33: 4664-4674, 2014.

16. Javelaud D, Alexaki VI, Dennler S, Javelaud D, Alexaki VI and Dennler S: TGF- $\beta /$ SMAD/GLI2 signaling axis in cancer progression and metastasis. Cancer Res 71: 5606-5610, 2011.

17. Moses $\mathrm{H}$ and Barcellos-Hoff MH: TGF-beta biology in mammary development and breast cancer. Cold Spring Harb Perspect Biol 3: a003277, 2011.

18. Drabsch Y and ten Dijke P: TGF- $\beta$ signaling in breast cancer cell invasion and bone metastasis. J Mammary Gland Biol Neoplasia 16: 97-108, 2011.

19. Connolly EC, Freimuth J and Akhurst RJ: Complexities of TGF- $\beta$ targeted cancer therapy. Int J Biol Sci 8: 964-978, 2012

20. Kang JS, Liu C and Derynck R: New regulatory mechanisms of TGF-beta receptor function. Trends Cell Biol 19: 385-394, 2009.

21. Wilczynska A and Bushell M: The complexity of miRNAmediated repression. Cell Death Differ 22: 22-33, 2015.

22. Yang F, Zhang W, Shen Y and Guan X: Identification of dysregulated microRNAs in triple-negative breast cancer (Review). Int J Oncol 46: 927-932, 2015.
23. Farazi TA, Horlings HM, Ten Hoeve JJ, Mihailovic A, Halfwerk H, Morozov P, Brown M, Hafner M, Reyal F, van Kouwenhove M, et al: MicroRNA sequence and expression analysis in breast tumors by deep sequencing. Cancer Res 71: 4443-4453, 2011.

24. Zhang K, Zhang Y, Liu C, Xiong Y and Zhang J: MicroRNAs in the diagnosis and prognosis of breast cancer and their therapeutic potential (Review). Int J Oncol 45: 950-958, 2014.

25. Volinia S, Calin GA, Liu CG, Ambs S, Cimmino A, Petrocca F, Visone R, Iorio M, Roldo C, Ferracin M, et al: A microRNA expression signature of human solid tumors defines cancer gene targets. Proc Natl Acad Sci USA 103: 2257-2261, 2006.

26. Yan LX, Huang XF, Shao Q, Huang MY, Deng L, Wu QL, Zeng YX and Shao JY: MicroRNA miR-21 overexpression in human breast cancer is associated with advanced clinical stage, lymph node metastasis and patient poor prognosis. RNA 14: 2348-2360, 2008 .

27. Huang TH, Wu F, Loeb GB, Hsu R, Heidersbach A, Brincat A, Horiuchi D, Lebbink RJ, Mo YY, Goga A, et al: Up-regulation of miR-21 by HER2/neu signaling promotes cell invasion. J Biol Chem 284: 18515-18524, 2009.

28. Qi L, Bart J, Tan LP, Platteel I, Sluis T, Huitema S, Harms G, $\mathrm{Fu}$ L, Hollema $\mathrm{H}$ and Berg A: Expression of miR-21 and its targets (PTEN, PDCD4, TM1) in flat epithelial atypia of the breast in relation to ductal carcinoma in situ and invasive carcinoma. BMC Cancer 9: 163, 2009.

29. Li T, Li D, Sha J, Sun P and Huang Y: MicroRNA-21 directly targets MARCKS and promotes apoptosis resistance and invasion in prostate cancer cells. Biochem Biophys Res Commun 383: 280-285, 2009.

30. Zhu S, Wu H, Wu F, Nie D, Sheng S and Mo YY: MicroRNA-21 targets tumor suppressor genes in invasion and metastasis. Cell Res 18: 350-359, 2008.

31. Han M, Liu M, Wang Y, Mo Z, Bi X, Liu Z, Fan Y, Chen X and $\mathrm{Wu} \mathrm{C}$ : $\mathrm{Re}$-expression of miR-21 contributes to migration and invasion by inducing epithelial-mesenchymal transition consistent with cancer stem cell characteristics in MCF-7 cells. Mol Cell Biochem 363: 427-436, 2012.

32. Chun HK, Jung KU, Choi YL, Hong HK, Kim SH, Yun SH, Kim HC, Lee WY and Cho YB: Low expression of transforming growth factor beta-1 in cancer tissue predicts a poor prognosis for patients with stage III rectal cancers. Oncology 86: 159-169, 2014.

33. Li Q, Zhang D, Wang Y, Sun P, Hou X, Larner J, Xiong W and Mi J: miR-21/Smad 7 signaling determines TGF- $\beta 1$-induced CAF formation. Sci Rep 3: 2038, 2013.

34. Wang JY, Gao YB, Zhang N, Zou DW, Wang P, Zhu ZY, Li JY, Zhou SN, Wang SC, Wang YY, et al: miR-21 overexpression enhances TGF- $\beta 1$-induced epithelial-to-mesenchymal transition by target smad7 and aggravates renal damage in diabetic nephropathy. Mol Cell Endocrinol 392: 163-172, 2014.

35. Petrović N, Mandušić V, Dimitrijević B, Roganović J, Lukić S, Todorović L and Stanojević B: Higher miR-21 expression in invasive breast carcinomas is associated with positive estrogen and progesterone receptor status in patients from Serbia. Med Oncol 31: 977, 2014.

36. Han M, Wang Y, Liu M, Bi X, Bao J, Zeng N, Zhu Z, Mo Z, Wu C and Chen X: MiR-21 regulates epithelial-mesenchymal transition phenotype and hypoxia-inducible factor-1 $\alpha$ expression in third-sphere forming breast cancer stem cell-like cells. Cancer Sci 103: 1058-1064, 2012.

37. Marino AL, Evangelista AF, Vieira RA, Macedo T, Kerr LM, Abrahão-Machado LF, Longatto-Filho A, Silveira HC and Marques MM: MicroRNA expression as risk biomarker of breast cancer metastasis: A pilot retrospective case-cohort study. BMC Cancer 14: 739, 2014.

38. Petrović N, Mandušić V, Stanojević B, Lukić S, Todorović L, Roganović J and Dimitrijević B: The difference in miR-21 expression levels between invasive and non-invasive breast cancers emphasizes its role in breast cancer invasion. Med Oncol 31: 867, 2014

39. Chen J and Wang X: MicroRNA-21 in breast cancer: Diagnostic and prognostic potential. Clin Transl Oncol 16: 225-233, 2014.

40. Azuma H, Ehata S, Miyazaki H, Watabe T, Maruyama O, Imamura T, Sakamoto T, Kiyama S, Kiyama Y, Ubai T, et al: Effect of Smad7 expression on metastasis of mouse mammary carcinoma JygMC(A) cells. J Natl Cancer Inst 97: 1734-1746, 2005. 